\title{
Effect of glycemic index on obesity control
}

Elisângela Vitoriano Pereira', Jorge de Assis Costa',

Rita de Cássia Gonçalves Alfenas'

\begin{abstract}
Objective: Evaluate the effect of glycemic index (GI) on biochemical parameters, food intake, energy metabolism, anthropometric measures and body composition in overweight subjects. Materials and methods: Simple blind study, in which nineteen subjects were randomly assigned to consume in the laboratory two daily low $\mathrm{GI}(\mathrm{n}=10)$ or high $\mathrm{GI}(\mathrm{n}=9)$ meals, for forty-five consecutive days. Habitual food intake was assessed at baseline. Food intake, anthropometric measures and body composition were assessed at each 15 days. Energy metabolism and biochemical parameters were evaluated at baseline and the end of the study. Results: Low GI meals increased fat oxidation, and reduced waist circumference and HOMA-IR, while high GI meals increased daily dietary fiber and energy intake compared to baseline. There was a higher reduction on waist circumference and body fat, and a higher increase on postprandial fat oxidation in response to the LGI meals than after high GI meals. High GI meals increased fasting respiratory coefficient compared to baseline and low GI meals. Conclusion: The results of the present study showed that the consumption of two daily low GI meals for forty-five consecutive days has a positive effect on obesity control, whereas, the consumption of high GI meals result has the opposite effect. Arch Endocrinol Metab. 2015;59(3):245-51
\end{abstract}

Keywords

Glycemic index; obesity; anthropometric measures; biochemical parameters; energy expenditure
1 Departamento de Nutrição e Saúde (DNS), Universidade Federal de Viçosa (UFV), Viçosa, MG, Brazil

Correspondence to:

Rita de Cássia Gonçalves Alfenas Universidade Federal de Viçosa

Departamento de Nutrição e Saúde Av. $\mathrm{PH}$ Rolfs, $\mathrm{s} / \mathrm{n}$

36570-000 - Viçosa, MG, Brazil

ralfenas@ufv.br

nyron27@hotmail.com

Received on May/16/2014 Accepted on Apr/16/2015

DOI: 10.1590/2359-3997000000045

\section{INTRODUCTION}

$\mathrm{O}$ besity prevalence, morbidity and mortality rates have significantly increased worldwide $(1,2)$. In 2005, World Health Organization (WHO) estimated an overweight and obesity prevalence of $60 \%$ and $20-30 \%$, respectively (1). It is estimated that by 2015 , the current number of obese people will double worldwide (1).

Several strategies have been proposed to prevent and treat obesity. However, diet is still the major therapeutic base against this disease (3). The results of several studies indicate a positive association between the consumption of high glycemic index (GI) diets versus obesity and related diseases manifestation $(2,3)$.

High GI foods are quickly digested and absorbed, resulting in high glycemic response, which in turn stimulates higher insulin secretion. High glycemic and insulinemic responses can affect appetite and energy metabolism, favoring body weight and body fat gain. On the other hand, low GI foods are digested and absorbed at slower rates, leading to lower glycemic and insulinemic responses, which in turn reduces satiety, food intake and increases adipose tissue mobilization.
Thus, GI has been considered as a possible tool to be used on obesity control (2).

The consumption of two low GI daily meals may lead to beneficial effects on body weight and body composition (4-7). Therefore, in the present study we assessed the effect of the consumption of two daily high or low GI meals on obesity control.

\section{MATERIALS AND METHODS}

\section{Subjects}

Eligibility included body mass index (BMI) between 27 and $35 \mathrm{~kg} / \mathrm{m}^{2}(8)$; stable body weight $( \pm 3 \mathrm{~kg})$ during the previous 3 months; age between 19 and 40 years; non-diabetic; not following any special diet; not using any medication that can affect energy metabolism or food intake; non-smoker, non-pregnant non-lactating; no allergy or intolerance to the foods supplied during the study.

All participants signed an informed consent form, filled out a recruitment questionnaire and the International Physical Activity Questionnaire (IPAQ) (9). 
The study was conducted in accordance with the guidelines set by the Declaration of Helsinki and the study protocol was approved by the Committee of Ethics in Human Research of the Federal University of Viçosa, following the Resolution 196/96 of the National Health Council, 10/10/1996, on human experimentation.

\section{Experimental design}

Sample size was calculated $(10)$ considering a $7 \%$ difference in waist circumference, and a statistical power of $80 \%$. The criterion for statistical significance was $5 \%$. A total of twenty one subjects were included in the study. Due to personal reasons, two of these subjects dropped out of the study. Nineteen subjects (four men and fifteen women), aged between 22 and 38 years, and which were overweight or obese (BMI between 27 and $35 \mathrm{~kg} / \mathrm{m}^{2}$ ) successfully completed the study. This was a simple blind study, in which the subjects were randomly assigned to one of two experimental groups: low GI $(\mathrm{n}=10)$ or high GI $(\mathrm{n}=9)$ consumed two daily high or low GI meals in the laboratory, for 45 consecutive days. The other meals were consumed under free living conditions, and for which the subjects were instructed to select mainly high or low GI foods, according to the experimental group to which they were assigned. All participants received a list discriminating low or high GI foods to help them in their food choice. This list was prepared based in the International GI Tables (11). Foods presenting GI $\leq 55$ or $\geq 70$ were considered low or high GI, respectively (12).

Participants' habitual food intake was assessed at baseline. At each 15 days of the study, food intake, anthropometric parameters and body composition were evaluated. Energy metabolism and biochemical parameters were assessed at baseline and at end of the study (Figure 1). Participants were asked to maintain constant level of physical activity during the study.

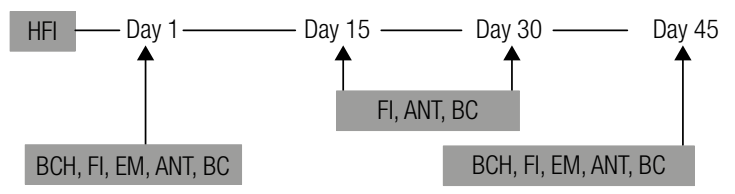

Figure 1. Study design. Habitual food intake (HFI) was assessed before the beginning of the study. Biochemical responses $(\mathrm{BCH})$ and energy metabolism (EM) were assessed on days 1 and 45. Food intake (FI), anthropometric measures (ANT), and body composition (BC) were evaluated on days $1,15,30$, and 45 .

\section{Test meals}

During the study 28 breakfast and afternoon snack preparations were served (14 high GI and 14 low GI), resulting in 7 different menu types per session, which were repeated along the experiment. The meals supplied $15 \%$ of each participant daily energy requirements (13), considering the physical activity index estimated by the IPAQ (9), adopting the physical activity factors recommended by the IOM (13) The meals GI were determined, following the method proposed by Food and Drug Administration (14). The tested preparations presented similar energy density, macronutrients, and dietary fiber contents (15).

\section{Food intake assessment}

Habitual food intake (before the beginning of the study), and food intake during the study was assessed using three non-consecutive days (two week days and a weekend day) dietary records (16). All subjects were trained to keep free-feeding dietary records before the beginning of the study, to increase reliability of the obtained information.

Each dietary record was reviewed with the subjects to ensure accuracy and completeness. The amounts of foods registered in household measures were converted into grams for the analysis of energy, macronutrient and dietary fiber intake, using the Diet Pro $^{\circledR}$ software - version $5.1 \mathrm{i}(17)$. The diet records were analyzed by a single person.

\section{Biochemical assessments}

After 12-hours overnight fasting, blood samples were collected immediately before (fasting condition) and at 30, 60 and 120 minutes after breakfast consumption.

Blood glucose and insulin concentrations were assessed by colorimetric-enzyme assay (Bioclin kit, Glucose Monoreagent K082, Basic Quibasa Química Ltd., MG, Brazil), and electro chemiluminescence immunoassay (Cobas kit, F. Hoffmann-La Roche Ltd., Basel, Switzerland), respectively. Leptin concentrations were assessed by radioimmunoassay using a Human Leptin RIA kit (Linco Research Inc., St. Louis, MO, USA).

Insulin-resistance level was determined using the HOMA-IR index (Homeostasis Model Assessment) (18): HOMA-IR = fasting insulinemia $(\mathrm{mcU} / \mathrm{dL}) \mathrm{x}$ fasting glycemia $(\mathrm{mmol} / \mathrm{L}) / 22.5$. HOMA-IR values higher than 2.71 was the cutoff point for insulin resistance (19). 


\section{Energy metabolism assessment}

For evaluation of resting energy expenditure (REE), subjects reported to the laboratory after 11 hours of fasting and remained rested for 30 minutes, under controlled environmental temperature $\left(25^{\circ} \mathrm{C}\right)$. REE was measured for 30 minutes. Next, participants consumed breakfast. $\mathrm{VO}_{2}(\mathrm{~L} / \mathrm{min})$ and $\mathrm{VCO}_{2}(\mathrm{~L} / \mathrm{min})$ were analyzed by indirect calorimetry (IC) (Deltatrac II, MBM200, Datex Instrumentarium Corporation, Helsinki, Finland), for the next 60 minutes, for diet-induced thermogenesis (DIT) determination (20). Respiratory coefficient $(\mathrm{RC})$ value was measured during the REE (fasting RC) and the DIT (postprandial RC) assessments. $\mathrm{RC}$ was obtained by dividing the produced $\mathrm{CO}_{2}$ by the consumed $\mathrm{VO}_{2}$.

Fat oxidation rates during the REE and DIT assessments were estimated using the following equation (21): Fat oxidation rate $(\mathrm{g} / \mathrm{min})=1.695 \times \mathrm{VO}_{2}-$ $1.701 \times \mathrm{VCO}_{2} . \mathrm{VO}_{2}$ and $\mathrm{VCO}_{2}$ values expressed in $\mathrm{ml} /$ min were divided by 1000 , to be expressed in $\mathrm{L} / \mathrm{min}$.

\section{Anthropometric and body composition assessments}

These evaluations were conducted in the morning, after at least 4-hours fasting. Body weight was assessed using a digital electronic scale, with $150 \mathrm{~kg}$ capacity and 0.05 $\mathrm{kg}$ accuracy (22), with individuals wearing light clothes. Height was determined using an anthropometer fixed to the wall, with $2 \mathrm{~m}$ extension and $0.5 \mathrm{~cm}$ scale (22). In both procedures, participants stood up barefoot, in erect position, with relaxed arms and head in the horizontal plan. BMI was calculated (23) dividing body weight by square height $\left(\mathrm{kg} / \mathrm{m}^{2}\right)$ and classified according to $\mathrm{WHO}(24)$.

Waist circumference (WC) and waist-hip ratio (WHR) were measured with a non-elastic, 2 m extension, $1 \mathrm{~mm}$ precision flexible tape measure. WC was obtained during normal breathing at the umbilical scar height. WHR was measured in the gluteal region, considering the longest horizontal perimeter between the waist and knees (25). The following cut-off points were considered as indicative of increased risk for developing metabolic complications associated with obesity: $\mathrm{WC} \geq$ $102 \mathrm{~cm}$ for men and WC $>88 \mathrm{~cm}$ for women (26) and WHR > 1.0 for men and WHR > 0.9 for women $(8)$.

Body composition was estimated through electrical bioimpedance method $-50 \mathrm{kHz}$ (BIA - Biodynamics, model 310, TBW). Measurements were taken in the right hemibody, with participants laid in dorsal decubitus on an isolating surface, without shoes, socks or accessories. The participant skin was cleaned with alcohol before placing the electrodes to the hand, wrist, foot and ankle. The day before evaluations, participants were instructed to maintain light physical activity; not to consume any liquid 4 hours prior to the test and to empty their bladders least 30 minutes before the test (27).

\section{Statistical analysis}

The statistical analyses were performed using the software SPSS (SPSS Inc., IL, USA), version 15. Significance level of $5 \%$ was adopted. Results are expressed as means \pm SD or SE.

Wilcoxon test was applied for comparison of variables between the pre and post intervention periods in each treatment. Mann-Whitney test was used to compare results between the two experimental groups. The positive areas under the glycemic, insulinemic and leptinemic response curves were calculated by the trapezoidal method, using the software SlideWrite 7.0 (Advanced Graphics Software, Inc.).

\section{RESULTS}

Participants were (mean \pm SD) $27 \pm 4$ years old, and had a BMI of $29.61 \pm 1.97 \mathrm{~kg} / \mathrm{m}^{2}$. The majority of the subjects were overweight $(63 \%, \mathrm{n}=12)$, had abdominal obesity $(68 \% ; n=13)$, and $37 \%(n=7)$ presented type I obesity presenting increased risk for metabolic complications. Baseline characteristics presented by the participants did not differ between groups (Table 1). There was an increase in energy intake $(\mathrm{P}=0,014)$ and in fiber consumption $(\mathrm{P}=0,008)$ in the high GI group during the study compared to the participants habitual consumption. There were no differences in macronutrient consumption between groups or at the end of the intervention compared to the beginning of the study within groups (Table 2).

Glucose, insulin and leptin responses did not differ in any of the assessed time points (fasting condition [0 minute] and at 30, 60 and 120 minutes after breakfast consumption). The area under the curves for these biochemical parameters also did not differ between treatments or between data obtained at the end of the study versus baseline (Figure 2A). At baseline two subjects of each experimental group had insulin resistance according the HOMA-IR value. Although glycemia and insulinemia were not affected in the study, while there was a reduction $(\mathrm{P}=0.027)$ in insulin resistance $(\mathrm{HO}-$ MA-IR) in the low GI group (Figure 2B), it increased $(\mathrm{P}=0,910)$ in the high GI group at the end of the study. 
Table 1. Mean \pm SD characteristics presented by the study participants at baseline, according to the experimental group

\begin{tabular}{lccc}
\hline \multirow{2}{*}{ Variables } & \multicolumn{2}{c}{ Experimental group } & \multirow{2}{*}{ P Value } \\
\cline { 2 - 3 } & Low glycemic index & High glycemic index & 0.967 \\
\hline Age (years) & $28 \pm 5$ & $26 \pm 3$ & 0.191 \\
BMI (kg/m²) & $29.9 \pm 2.1$ & $29.1 \pm 2.0$ & 0.870 \\
Body weight (kg) & $80.0 \pm 12.6$ & $79.1 \pm 12.2$ & 0.072 \\
Waist to hip ratio & $0.85 \pm 0.05$ & $0.85 \pm 0.06$ & 0.902 \\
Waist circunference (cm) & $95.18 \pm 8.51$ & $95.17 \pm 9.92$ & 0.071 \\
Body fat (\%) & $30.3 \pm 7.2$ & $27.9 \pm 3.4$ & 0.825 \\
Body fat (kg) & $22.9 \pm 5.9$ & $22.1 \pm 3.3$ & 0.791 \\
Lean mass (kg) & $56.1 \pm 13.0$ & $57.0 \pm 10.9$ & 0.796 \\
RER (kcal/day) & $1595 \pm 276$ & $1586 \pm 233$ & 0.838 \\
Fasting glycemia (mg/dL) & $82.5 \pm 5.5$ & $82.3 \pm 6.3$ & 0.806 \\
Fasting insulinemia (mcl/dL) & $9.3 \pm 4.8$ & $9.2 \pm 5.9$ & 0.325 \\
Fasting leptinemia (ng/dL) & $19.9 \pm 10.4$ & $15.2 \pm 9.1$ & 0.683 \\
HOMA-IR & $1.86 \pm 0.87$ & $1.92 \pm 1.37$ & \\
\hline
\end{tabular}

RER: resting energy expenditure; HOMA-IR: Homeostasis Model Assessment of Insulin Resistent.

The data presented above are not different according to study group by Mann-Whitney Test, $P \leq 0.05$.

Table 2. Mean \pm SD energy, macronutrients, and dietary fiber consumption, according to study group

\begin{tabular}{|c|c|c|c|c|}
\hline \multirow{2}{*}{ Variables } & \multicolumn{2}{|c|}{ Low GI $(n=10)$} & \multicolumn{2}{|c|}{ High GI (n = 9) } \\
\hline & Habitual & During the study' & Habitual & During the study ${ }^{1}$ \\
\hline Energy (kcal/dia) & $2257.7 \pm 729.7$ & $2143.6 \pm 608.5$ & $1752 \pm 495.9^{a}$ & $2006.3 \pm 540.7^{b}$ \\
\hline Carbohydrate (\%) & $47.7 \pm 9.1$ & $48.3 \pm 20.1$ & $51.1 \pm 7.2$ & $54.6 \pm 9.4$ \\
\hline Protein (\%) & $16.3 \pm 5.9$ & $16.1 \pm 3.7$ & $14.8 \pm 2.2$ & $12.7 \pm 2.0$ \\
\hline Protein (g/kg de peso) & $1.1 \pm 0.4$ & $1.1 \pm 0.3$ & $0.8 \pm 0.3$ & $0.8 \pm 0.3$ \\
\hline Fat (\%) & $36.2 \pm 7.5$ & $32.8 \pm 6.5$ & $31.2 \pm 4.8$ & $34.4 \pm 9.2$ \\
\hline Dietary fiber (g/dia) & $11.9 \pm 4.6$ & $12.0 \pm 3.7$ & $14.0 \pm 5.8^{\mathrm{a}}$ & $16.9 \pm 4.9^{b}$ \\
\hline
\end{tabular}

Gl: glycemic index. ${ }^{1}$ Mean of all dietary records obtained during the study. ${ }^{a, b}$ Different letters in the same line indicate statistical difference $(P \leq 0.05)$ by Wilcoxon test.
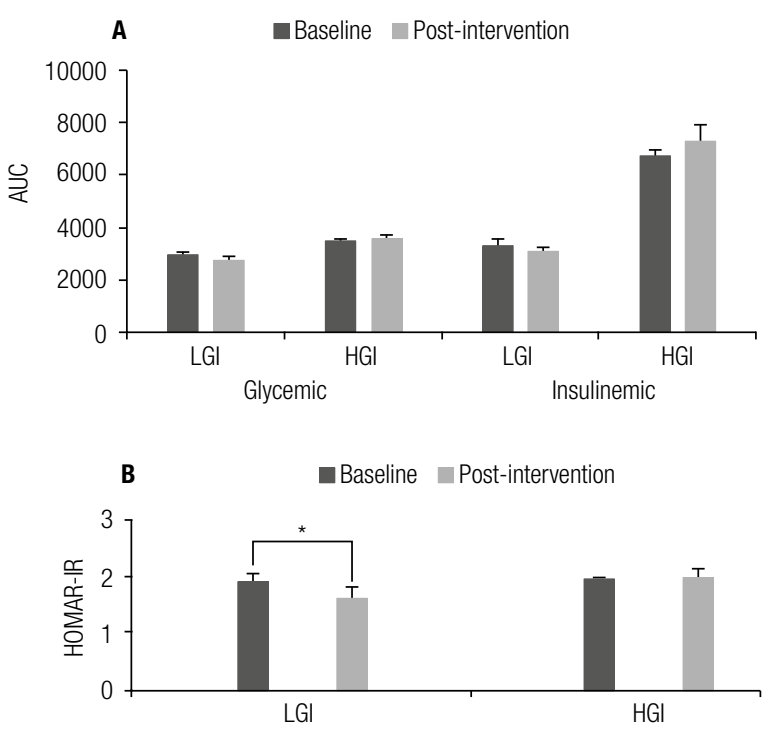

Figure 2. Mean \pm SE area under the glycemic and insulinemic curves (AUC) at baseline and after 45 consecutive days of consumption of low glycemic index (LGl) or high glycemic index (HGl) meals twice a day (A), and homeostasis model assessment for insulin resistance (HOMA-IR) at baseline and after the consumption of two daily LGI or HGl meals for 45 consecutive days (B). LGl HOMA-IR value at baseline is higher $\left({ }^{*} \mathrm{P}=\right.$ 0.027)than at the end of the study (Wilcoxon Test).
While insulin resistance reduced $50 \%(\mathrm{n}=1)$ in the low GI group, it increased $50 \%(\mathrm{n}=4)$ in the high GI group at the end of the study. REE and the DIT did not differ in response to the treatments of this study. While fasting $(\mathrm{P}=0.008)$ and postprandial $(\mathrm{P}=0.012)$ fat oxidation reduced in the high GI group, in the low GI group it increased $(\mathrm{P}=0.002)$ in the fasting period (Figure 3 ). There were no differences in the observed reductions ( $\Delta$ post-intervention) on HOMA-IR and fat oxidation (fasting and post-prandial) between treatments.

There was a significant $\mathrm{WC}(\mathrm{P}=0.037)$ reduction in response to the low GI treatment. The observed reductions ( $\Delta$ post-intervention) on WC $(\mathrm{P}=0.008)$ and on $\operatorname{WHR}(\mathrm{P}=0.050)$ in the low GI group was greater than the ones verified for the high GI group (Figure 4).

\section{DISCUSSION}

The quantity and quality of the ingested carbohydrate are the main determinants of postprandial glycemic 

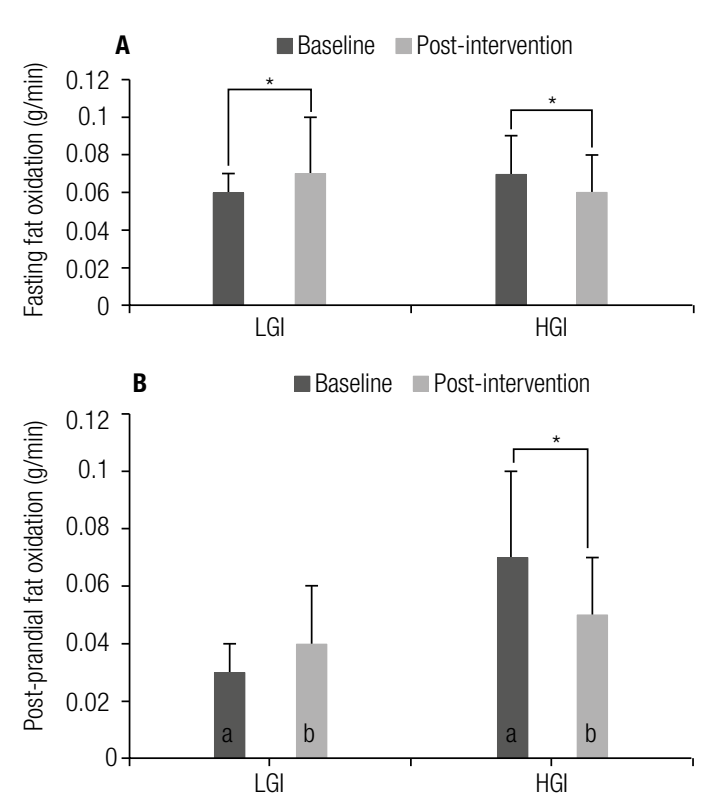

Figure 3. Mean \pm SD fasting $(\mathbf{A})$ and post-prandial (B) fat oxidation at baseline and after 45 consecutive days of consumption of low glycemic index (LGl) or high glycemic index (HGI) meals twice a day. While LGl fasting fat oxidation increased $(P=0.002)$, $H G$ fasting $(P=0.008)$ and post-prandial $(P=0.012)$ fat oxidation reduced after 45 consecutive days of consumption of test meals (Wilcoxon Test).

response, which in turn affects glycemic control $(4,5)$. In the present study, although no differences were observed in each assessed time point $(0,30,60$ or 120 minutes) or in the in the area under the glycemic and insulinemic response curves, HOMA-IR reduced after 45 consecutive days of consumption of two daily low GI meals. This result is relevant, since insulin resistance is considered the determining and triggering factor of metabolic syndrome and related diseases (28). Similar result was verified in a crossover study $(5)$ in which the consumption of diets differing in GI by seven women for 20 days led to an increase in insulin sensitivity in response to the low GI diets.

$\mathrm{RC}$ reflects the type of energy substrate oxidated. Fat oxidation reduces as RC increases (29). High fasting $\mathrm{RC}$ is the major factor involved in weight gain $(29,30)$. It has been suggested that the consumption of high GI diets leads to lower fat oxidation than of low GI ones (31). Such effect was noted in the present study. The consumption of high GI meals increased $\mathrm{RC}$ and reduced fasting and postprandial fat oxidation.
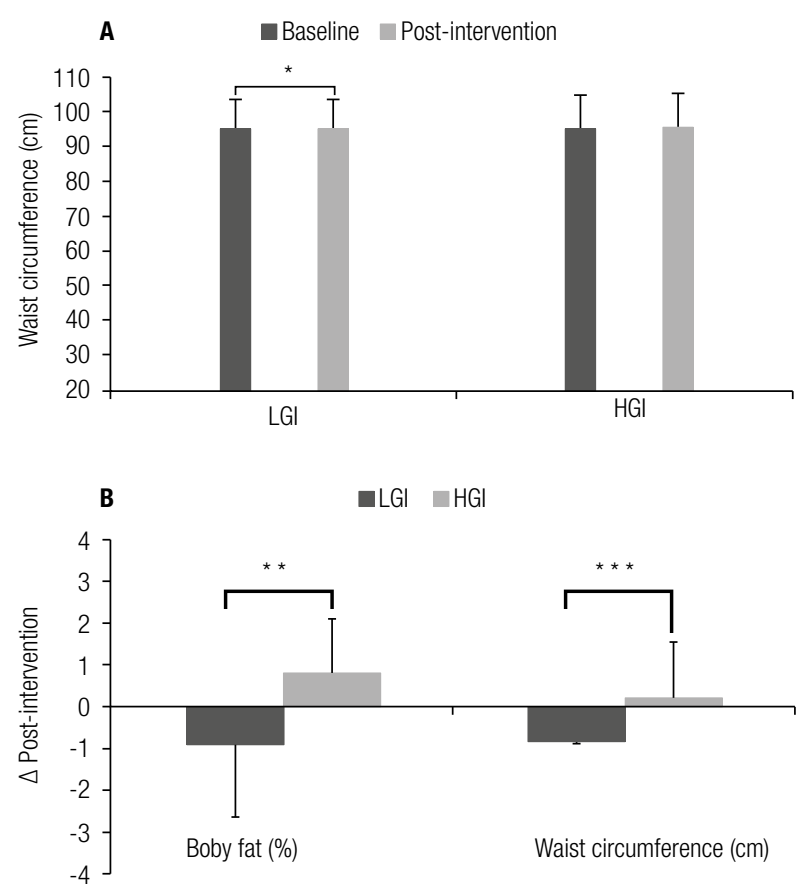

Figure 4. Mean $\pm S D$ waist circumference at baseline and after 45 consecutive days of consumption of low glycemic index (LGI) or high glycemic index ( $\mathrm{HGl}$ ) meals twice a day (A), and waist circumference and body fat changes ( $\triangle$ post-intervention) in response to the consumption of two daily LGl or HGI meals for 45 consecutive days (B). Waist circumference reduced ( ${ }^{\star} P=0.037$ ) after the consumption LGI meal (Wilcoxon Test) $(\mathbf{A})$. Waist circumference $\left({ }^{\star \star \star} P=0.008\right)$ and body fat $\left({ }^{\star \star} P=0.050\right)$ reduced after the consumption of the LGI meal compared to the HGI meal (MannWhitney Test) (B).

This reduction in fat oxidation in response to the high GI diet may be due to an increase in postprandial insulin secretion, which in turn inhibits lipolysis and favors lipogenesis (31). Consequently, this can be considered one of the mechanisms by which chronic consumption of high GI foods favors the increase in body fat content.

It has been claimed that while the consumption of high GI meals can increase appetite in subsequent meals, the ingestion of low GI ones may exert the opposite effect (32). On the other hand, dietary fibers can enhance satiety and decrease food intake. These responses may be related to the fibers effect in the increase of stomach distension and of gut hormones release (such as GLP-1), enhancing satiety and decreasing energy intake (33). We verified an increase in daily energy intake in the high GI group, regardless of the dietary fiber consumption increase. This result indicates that the effect of dietary fiber may not be strong enough to surpass the increasing energy intake effect of high GI meals.

Although body weight was not significantly affected after the interventions, while the low GI group presen- 
ted a mean weight loss of $960 \mathrm{~g}$, the high GI group gained 430 g. Similar result was observed in another crossover study (6), in which seventeen subjects consumed two daily high GI or low GI meals, for 30 consecutive days each. A non-significant mean weight loss of $580 \mathrm{~g}$ was verified in response to the low GI meals compared to a mean weight gain of $130 \mathrm{~g}$ to the high GI meals. The results of these two last studies suggest that a longer intervention period may result in a more expressive body weight reduction, if this type of response is maintained.

A reduction in WHR and WC was also observed after the consumption of low GI meals in this study. These results are particularly important, given that excess adipose tissue and mainly its accumulation in the abdominal region is associated with several undesirable metabolic diseases (34). WC has been pointed as the best anthropometric indicator of visceral fat accumulation. Excessive accumulation of this type of fat favors the occurrence of glycemic and insulinemic disorders, which is considered an important cardiovascular risk factor (35). In a meta-analysis (7) involving 37 prospective cohort studies, the consumption of low GI diets was associated with a reduction of chronic diseases risk, such as type 2 diabetes and cardiovascular diseases, regardless of age, sex, BMI, smoking, alcohol consumption, and physical activity level. On the other hand, glycemia increase after the consumption of high GI meals was considered responsible for the progression of these diseases.

Visceral fat presents metabolic and functional characteristics, which are distinct from those presented in response to fat located in other anatomical body regions. Visceral fat has a higher lipolytic potential that causes hepatic insulin resistance by lipotoxicity, affecting insulin degradation, favoring the incidence of hyperinsulinemia and subsequent peripheral insulin resistance, leading to diabetes mellitus. In addition, excessive abdominal fat, increases free fatty acids release and pro-inflammatory cytokines production, such as tumor necrosis factor-alpha (TNF- $\alpha$ ) and interleukin-6 (36). Hence, the reduction of body fat, especially in the abdominal region is of fundamental importance for glycemic control.

The main limitation of this study was the use of an indirect method to assess insulin resistance (HOMA-IR). However, we must highlight that the gold-standard method to assess insulin sensitivity (hyperinsulinemiceuglycemic clamp) is invasive and expensive. On the other hand, besides being easy to use, HOMA-IR is a validated method to assess insulin sensitivity (37). We also used electrical bioimpedance, an indirect method to assess body composition. Although underwater densitometry is the gold-standard method for that type of assessment it is a complex and high cost method. For accurate data it requires highly trained technicians, standardized operations and facilities, besides having motived subjects, which must exhale prior to submersion in a water tank. On the contrary, electrical bioimpedance is a low cost method, it does not require cumbersome apparatus, and it has a good correlation with underwater densitometry (38).

It has been claimed that the consumption of two low GI meals would lead to beneficial effects on body weight and body composition (4-7). To test that, the subjects of the present study consumed in the laboratory two daily high or low GI meals. We also tested if the beneficial effect of GI would still be observed if meal were consumed under free living conditions. Therefore, to test GI clinical usefulness, the subjects of our study were instructed to eat mainly high or low GI foods, according to the experimental group to which they were assigned. Even though these foods were not supplied to the subjects, they received a list discriminating low or high GI foods to guide them to select the foods. This procedure was adopted to mimic what usually happens in a regular nutrition education process. To our knowledge no other study adopted such design.

The results of this study indicate that the consumption of low GI foods can promote beneficial effects for the prevention and treatment of obesity; whereas, high GI foods has an opposite effect. Further well-designed studies are necessary to elucidate the physiologic mechanisms responsible for the observed effects.

Disclosure: no potential conflict of interest relevant to this article was reported.

\section{REFERENCES}

1. World Health Organization. Noncommunicable Diseases Country Profiles 2011. Geneva: World Health Organization; 2011.

2. Marsh K, Brand-Miller J. Glycemic index, obesity and chronic disease. Am J Lifestyle Med. 2008;2:142-50.

3. Abete I, Parra D, Martinez JA. Energy-restricted diets based on a distinct food selection affecting the glycemic index induce different weight loss and oxidative response. Clin Nutr. 2008;27:545-51.

4. Brand-Miller JC, Foster-Powell K. Diets with a low glycemic index from theory to pratice. Nutr Today. 1999;34:4-72.

5. Clapp JF, Lopez B. Low versus high-glycemic index diets in women: effects on caloric requirement, substrate utilization and insulin sensitivity. Metab Syndr Relat Disord. 2007;5:231-42. 
6. Costa JA, Alfenas RCG. The consumption of low glycemic meals reduces abdominal obesity in subjects with excess body weight. Nutr Hosp. 2012;27:1162-7.

7. Barclay AW, Petocz P, McMillan-Price J. Glycemic index, glycemic load, and chronic disease risk - a meta-analysis of observational studies. Am J Clin Nutr. 2008;87:627-37.

8. Foz M, Barbany M, Remesar X, Carrillo M, Aranceta J, GarcíaLuna PP, et al. Consenso SEEDO'2000 para la evaluación del sobrepeso y la obesidad y elestablecimiento de criterios de intervenciónterapéutica. Med Clin (Barc). 2000;115:587-97.

9. Ainsworth BE, Haskell WL, Whitt MC, Irwin ML, Swartz AM, Strath SJ, et al. Compendium of physical activities: an update of activity codes and MET intensities. Med Sci Sports Exerc. 2000;32(9 Suppl):S498-516.

10. Mera R, Thompson H, Prasad C. How to calculate sample size for an experiment: a case-based description. Nutr Neurosci. 1998;1:87-91.

11. Atkinson FS, Foster-Powell K, Brand-Miller JC. International tables of glycemic index and glycemic load values: 2008. Diabetes Care. 2008;31:2281-3.

12. Brand-Miller J, Wolever TMS, Foster-Powell K, Colagiuri S. The new glycemic index revolution: the authoritative guide to the glycemic index. Marlowe \& Company; 2003.

13. Institute of Medicine of the National Academies. Dietary reference intakes for energy, carbohydrate, fiber, fat, fatty acids, cholesterol, protein, and aminoacids. [internet]. Washington: The National Academy Press; [updated on 2005]. Available at: http://books.nap. edu/catalog.php?record_id=10490. Accessed on: Mar. 15, 2013.

14. Food and Agricultural Organization of the United Nations. Carbohydrates in human nutrition. Roma: report of a Joint FAO/WHO Expert Consultation; 1998.

15. Costa JA. Efeito do índice glicêmico dos alimentos nas medidas antropométricas, na composição corporal e na ingestão alimentar [dissertation]. Viçosa: Universidade Federal de Viçosa; 2009.

16. Thompson FE, Byers T. Dietary assessment resource manual. Am J Clin Nutr. 1994;124:2245-317.

17. Dietpro 5.1i profissional [CD-ROM] version 5.1i. Viçosa: Agromídia Software Sistemas; 2007.

18. Matthews DR, Hosker JP, Rudenski AS. Homeostasis model assessment: insulin resistance and cell function from fasting plasma glucose and insulin concentrations in man. Diabetologia. 1985;28:412-9.

19. Geloneze B, Repetto EM, Geloneze SR. The threshold value for insulin resistance (HOMA IR) in an admixtured population. IR in the Brazilian Metabolic Syndrome Study. Diabetes Res Clin Pract. 2006;72:219-20.

20. Labayen I, Forga L, Martínez JA. Nutrient oxidation and metabolic rate as affected by meals containing different proportions of carbohydrate and fat in healthy young women. Eur J Nutr. 1999;38:58-66.

21. Frayn KN. Calcutation of substrate oxidation rates in vivo from gaseous exchange. J Appl Physiol. 1983;55:628-34.
22. Jelliffe DB. Evolución del estado de nutrición de lacomunidad. Ginebra, Organización Mundial de la Salud; 1968.

23. Bray GA, Gray DS. Obesity I: Phathogenesis. Western J Med. 1988;149:429-41.

24. World Health Organization. Defining the problem of overweight and obesity. In: World Health Organization. Obesity: preventing and managing the global epidemic: report of a Who Consultation. Geneva: WHOTechnical Report Series, 894; 2000.

25. Picon PX, Leitão CB, Gerchman F. Medida da cintura e razão cintura/quadril e identificação de situações de risco cardiovascular: estudo multicêntrico em pacientes com diabetes melito tipo 2. Arq Bras Endocrinol Metab. 2007;51:443-9.

26. Salas-Salvadó J, Rubio MA, Barbany M, Moreno B, Aranceta J, Bellido D, et al. Consenso SEEDO'2007 para la evaluación del sobrepeso y la obesidad y el establecimiento de criterios de intervención terapéutica. Med Clin (Barc). 2007;128(5):184-96.

27. Heyward VH, Stolarczyk LM. Avaliação da composição corporal aplicada. São Paulo: Manole; 2000.

28. Pereira MA, Jacobs Jr DR. Effect of whole grains on insulin sensitivity in overweight hyperinsulinemic adults. Am J Clin. 2002;75:848-55.

29. McArdle WD, Kath FKI, Kath VL. Fisiologia do exercício: energia, nutrição e desempenho humano. 5.ed. Rio de Janeiro: Guanabara Koogan; 2003.

30. McCarty MF.The origins of western obesity: a role for animal protein? Med Hypotheses. 2000;54:488-594.

31. Febbraio MA, Keenan J, Angus D. Pre-exercise carbohydrate ingestion, glucose kinetics, and muscle glycogen use: effect of the glycemic index. J Appl Physiol. 2000;89:1845-51.

32. Howarth N C, Saltzman E, Roberts SB. Dietary fiber and weight regulation. Nutr Rev. 2001;59:129-39.

33. Ebbeling CB, Leidig MM, Sinclair KB, Hangen JP, Ludwig DS. A reduced-glycemic load diet in the treatment of adolescent obesity. Arch Pediatr Adolesc Med. 2003;157:773-9.

34. Rezende FAC, Rosado LEFPL, Priore SE. Aplicabilidade de equações na avaliação da composição corporal da população brasileira. Rev Nutr. 2006;19:357-67.

35. Martins IS, Marinho SP. O potencial diagnóstico dos indicadores da obesidade centralizada. Rev Saúde Públ. 2003;37:760-7.

36. Silva JLT, Barbosa DS, Oliveira JA. Distribuição centrípeta da gordura corporal, sobrepeso e aptidão cardiorrespiratória: associação com sensibilidade insulínica e alterações metabólicas. Arq Bras Endocrinol Metab. 2006;50:1034-40.

37. Vasques ACJ, Rosado LEFPL, Alfenas RCG, Genoleneze B. Análise crítica do uso dos índices do Homeostasis Model Assessment (HOMA) na avaliação da resistência à insulina e capacidade funcional das células pancreáticas. Arq Bras Endrocrinol Metab. 2008;52:32-9.

38. Eickemberg M, Oliveira CC, Roriz AKC, Sampaio LR. Bioimpedância elétrica e sua aplicação em avaliação nutricional. Rev Nutr. $2011 ; 24: 883-93$ 